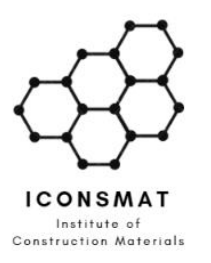

Content list available at ICONSMAT

Journal of Construction Materials

Journal homepage: $\underline{w w w . i c o n s m a t . c o m . a u / p u b l i c a t i o n ~}$
Article history:

Received 5 September 2020

Received in revised form

7 September 2020

Accepted 8 September 2020

Available online

2 October 2020

\title{
Experimental investigation on shear behaviour of fibre reinforced concrete beams using steel fibres
}

G. Beulah Gnana Ananthi ${ }^{1 *}$, A. Jaffer Sathick ${ }^{1}$, M. Abirami ${ }^{1}$

${ }^{1}$ Anna University, India

*Corresponding author: G. Beulah Gnana Ananthi; E: beulahceg@gmail.com

\begin{abstract}
Fibre reinforced concrete (FRC) has been widely used in industrial pavements and non-structural elements such as pipes, culverts, tunnels, and precast elements. The strengthening effect of fibres in the concrete matrix is achieved primarily due to the bridging effect of fibres at the crack interfaces. The workability of the concrete was reduced on addition of high percentages of steel fibres. The optimum percentage of addition of steel fibres varies with its aspect ratio. For this study, $1 \%$ addition of steel has resulted to be the optimum percentage for both Hooked and Crimped Steel Fibres and was added to the beam specimens. The fibres restrain efficiently the cracks and take up residual stresses beyond the cracking. In this sense, diagonal cracks are effectively stitched up by fibres crossing it. The failure of beams within the shear failure range changed from shear to flexure in the presence of sufficient steel fibre quantity. The shear strength is increased with the addition of steel fibres and had exceeded the enhancement obtained with the transverse reinforcement. However, such increase is not directly in proportion with the quantity of fibres used. Considering all the clarification made in the present experimental investigation, it is concluded that $1 \%$ of crimped steel fibres with an aspect ratio of 50 is the best type of steel fibres for replacement of transverse stirrups in high strength concrete beams when compared to the steel fibres with hooked ends.
\end{abstract}

DOI: 10.36756/JCM.v2.1.5 @2020 Institute of Construction Materials

\section{Keywords}

Fibre reinforced concrete; steel fibre; shear strength; crack pattern. 


\section{Introduction}

Shear behaviour of structural concrete is a research topic that continues to have much interest despite the abundance of literature. Since the principle of shear in reinforced concrete remains insufficiently explained in most of the research works and not a widely accepted solution unifying all the strength factors influencing shear behaviour of reinforced concrete members that exists till now.

In engineering projects, the high-strength concrete is essential that has concrete components and must resist high compressive loads [10]. It is typically used in the erection of high-rise structures. It has been used in components such as columns (especially on lower floors where the loads will be greatest), shear walls, and foundations. From the literature, it is seen that not only the special concrete has made such projects feasible due to load capacity, it has also allowed for the reduction of column and beam dimensions [8], lower dead loads result, reduction of the loads associated with foundation design. Also, owners benefit economically since the amount of rentable floor space, primarily on the lower floors, increases as the space occupied by the columns decreases. They are also rarely used in bridge applications as well. High-strength concrete permits reinforced or pre-stressed concrete girders to span greater lengths than normal strength concrete girders [12]. Also, the greater individual girder capacities may enable a decrease in the number of girders required. Thus, an economical advantage is created for concrete producers in that concrete is promoted for use in a particular bridge project as opposed to steel.

The properties of fibres play an important role in determining the predominant mechanism of failure as well as on the macroscopic behaviour of the cracked FRC members [6]. While the small-sized (micro) steel fibre in the concrete mix enhances the compressive and splitting tensile strengths, the large-sized (macro) fibres, on the other hand, yield the opposite mechanical effects [4], [9]. For the enhancement of workability and modification of electrical properties, carbon nano fibres had also attracted a lot of attention in the recent years[1, 2].

Usually, plain concrete fails in a brittle manner at the occurrence of cracking [5]. The addition of steel fibres helps the concrete to carry stresses well beyond the cracking, thus maintaining the structural integrity [7]. The effectiveness of steel fibre reinforced concrete (SFRC) [11] in improving various mechanical properties of concrete largely depends on the fibre dosage, fibre aspect ratio, amount of longitudinal steel, tensile strength of fibres and concrete compressive strength [3]. The effect of quantity of each type of fibre on the mechanical properties of FRC has been studied previously. However, limited studies have been carried out to study the behaviour of RC beams with different steel fibres in the concrete mix in the presence of conventional longitudinal reinforcement.

\section{Literature review}

Sauer et al. [13] have investigated shear capacity of SFRC beams without stirrups. The research checked the effectiveness of steel fibres on the shear capacity of beams without stirrups. A comparison between the ultimate shear force and the calculated shear force showed that the German guideline estimates the shear capacity on the safe side. However, there is still potential for optimization. The main parameters for calculating shear force were analyzed. These are the concrete compressive strength, the longitudinal reinforcement ratio, the effective depth, and the web width. The tests results show a slight increase over increasing longitudinal reinforcement ratio. Based on the comparison between test results excluding and including steel fibres for pre-stressed beams, the authors concluded that steel fibres also have an influence on shear capacity. Mohamed Zakaria et al.[14] have investigated on shear cracking behaviour in reinforced concrete beams with shear reinforcement. the author has emphasized 
on shear cracking behaviour of reinforced concrete beams. The investigations included the effects of the various influential parameters on the spacing between shear cracks and the relationship between shear crack width and stirrup strain at the intersection with shear cracks. The investigations revealed that shear crack width proportionally increases with both the strain of shear reinforcement and with the spacing between shear cracks. The experimental results revealed that the diagonal crack spacings and openings are influential on side concrete cover to stirrup, stirrup spacing and/or stirrup configuration and longitudinal reinforcement. The experimental results presented are helpful in the development of a rational shear crack displacement prediction method in existing design codes.

\section{Experimental investigation}

cracking and modes of failure of the beams

On loading the HSC beams, vertical flexural cracks are the first to develop vertically in the tension zone at the maximum moment region. On subsequent loading (from $60 \%$ to $70 \%$ of ultimate), diagonal cracks formed within the shear span in the direction of the support and the loading point. With the presence of sufficient steel fibres, the diagonal cracks occurred at relatively higher loads by comparison to those in beams without fibres or with insufficient quantities of fibres (Table 1); they were effectively restrained and stayed relatively narrower on further increase in loads. Failure was also by shear but in a ductile manner and at relatively higher loads when steel fibres. The fibres effectively reduced the openings of cracks by taking up the tensile stress after cracking.

With high fibre volume fractions, some fibre clusters will be formed in the fresh state, making fibres less effective at the hardened state. The effectiveness of fibres after cracking is exhibited through the deformed shapes of their anchored ends which appear in as completely straightened. Fibres not crossing the crack remain unstressed, keeping their original shape.

Table 1 Amount of steel fibre added

\begin{tabular}{cllllllc}
\hline Type of reinforcement & $\mathrm{a} / \mathrm{d}$ & $\rho_{w}(\%)$ & $\rho_{f}(\%)$ & $\mathrm{I}_{\mathrm{f}} / \mathrm{d}_{\mathrm{f}}$ & $\mathrm{P}_{\mathrm{d}}(\mathrm{kN})$ & $\mathrm{P}_{\mathrm{u}}(\mathrm{kN})$ & Modes of failure \\
\hline Normal & 2.81 & 0.90 & 0 & - & 103.15 & 147.35 & $\mathrm{~S}$ \\
Hooked & 2.81 & 0 & 1 & 50 & 114.88 & 159.47 & F-S \\
Crimped & 2.81 & 0 & 1 & 50 & 118.39 & 169.13 & F-S \\
\hline
\end{tabular}

$* \rho_{w}$-transverse reinforcement ratio, $\rho_{f}$-fibre content, $\mathrm{P}_{\mathrm{d}}-$ Diagonal cracking load, $\mathrm{P}_{\mathrm{u}}-$ Ultimate load.

**Notation of failure mode: S-Shear; F- Flexural; F-S Flexural and shear

From the load-deflection curves, it can be seen that the behaviour of the beams without stirrups and reinforced with steel fibres is identical to that of the beams with stirrups and without steel fibres. It generally presents three main stages:

- A linear behaviour, where the deflection is proportional to the load; this is the elastic stage up to the occurrence of the first crack.

- A second stage of linearity where the slope of the curve is slightly reduced under the influence of the first flexural crack. The deflection increases with the load but at a relatively higher rate. After full cracking and development of the cracks, beams without fibres lose their rigidity and fail without undergoing further sufficient deflection (see Fig. 2) compared to those containing steel fibres. 
- A third stage where the non-linear deflection becomes more important until failure in relation to the load which remains almost constant; this corresponds to the plastic flow or plastic behaviour of the concrete beam inducing important plastic deformations before failure.

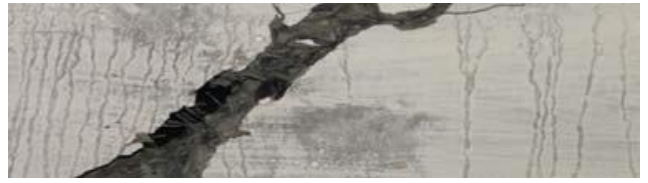

Figure 1 Fibres stitching of a diagonal crack

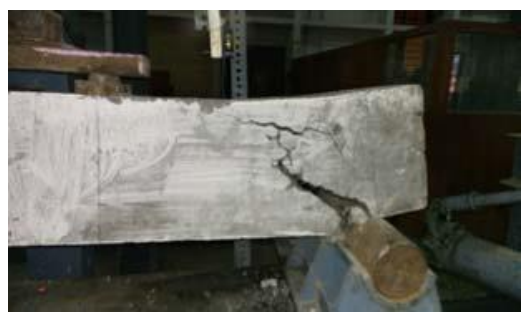

Figure 2 Brittle shear failure (without steel fibres)

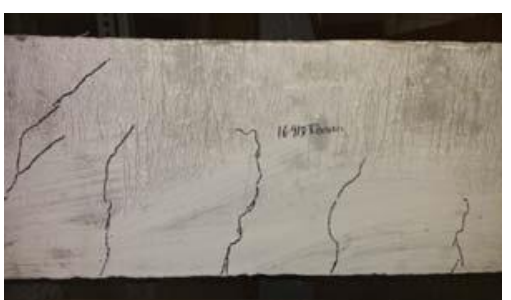

Figure 1 Ductile flexural (with steek fibres)

\section{Compressive Strength}

Compression test is the most common test conducted for pavement block. After immersed in water at room temperature for 24 hours, the block is placed horizontally with flat surface facing on the top and placed carefully in between the plates of compression testing machine.

Load is applied uniformly on the concrete block. The load at which the block fails or crushes is noted. The above observations are tabulated for three blocks, and the average strength of block is calculated.

\section{Split Tensile Test}

The tensile strength is one of the basic and important properties of the concrete. The concrete is not usually expected to resist the direct tension because of its low tensile strength and brittle nature. However, the determination of tensile strength of concrete is necessary to determine the load at which the concrete members may crack. The cracking is a form of tension failure.

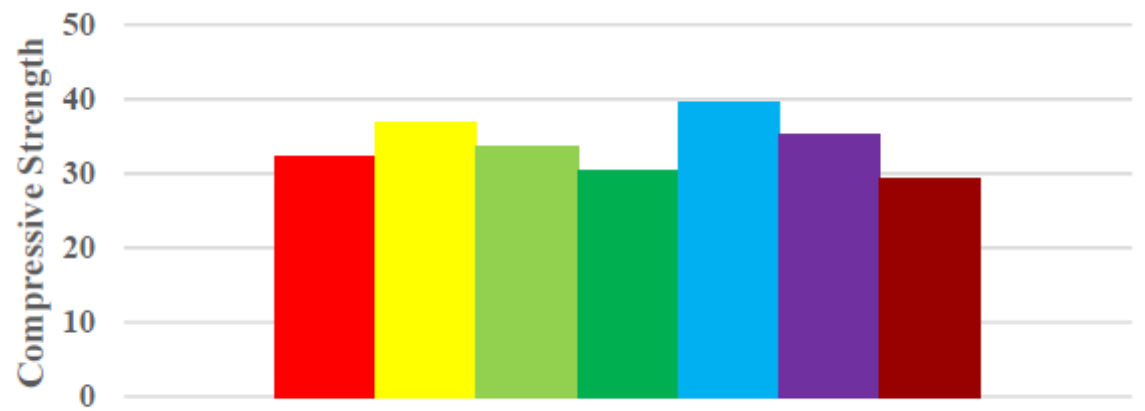

Type of Cube

\section{normal}

Hooked, 1\%

Hooked, 1.5\%

- Hooked, $2 \%$

- Crimped, $1 \%$

-Crimped, $1.5 \%$

-Crimped, $2 \%$

Figure 4 Graph representing compressive strength

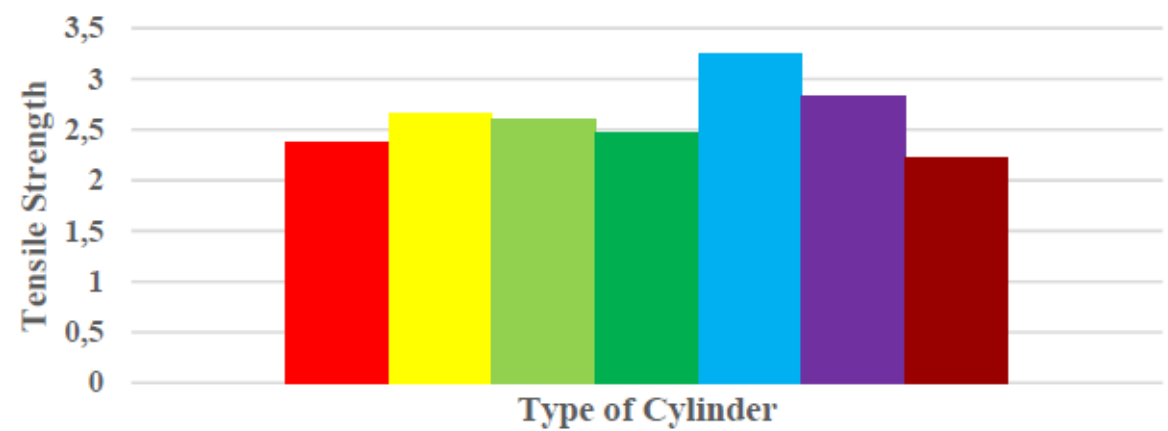

normal

Hooked, $1 \%$

- Hooked, 1.5\%

- Hooked, $2 \%$

- Crimped, $1 \%$

-Crimped, $1.5 \%$

nCrimped, $2 \%$

Figure 5 Graph representing tensile strength of FRC 


\section{Conclusion}

From the present experimental work on the effect of different steel fibres on the loaded behaviour of high strength concrete, particularly on shear, the following conclusions can be made:

- The addition of steel fibres increases the compressive strength and tensile strength of high strength concrete when compared to the high strength concrete without steel fibres.

- However, such improvement does not seem to be in proportion with the quantity of fibres used. The workability of the concrete gets reduced on addition of high percentages of steel fibres, i.e. addition of $1.5 \%$ and $2 \%$ of steel fibres exhibit less compressive strength and tensile strength when compared to addition of $1 \%$ of steel fibres.

- The amount of addition of steel fibres differs with its aspect ratio. This experimental work concluded that $1 \%$ was best to be the optimum percentage for both Hooked and Crimped Steel Fibres being used in the same beam specimens.

- The fibres hold back efficiently the cracks and adopt residual stresses beyond the cracking. In this sense, diagonal cracks can be effectively stitched by the fibres crossing it. In the existence of optimum steel fibre quantity, the collapse of beams within the shear failure range changed from shear to flexure. By changing the failure mode, they increased the ultimate load capacity of high strength concrete beams.

- The shear strength is improved with the addition of steel fibres and had exceeded the improvement obtained with the transverse reinforcement. Conversely, such raised in amount is not directly in proportion with the quantity of fibres used. Indeed, with higher fibre quantities, more fibres remain unstressed, forming clusters or not correctly orientated within concrete. This calls for an efficiency factor $k$ depending on the fibre quantity used. The aspect ratio of the fibres and the quality of bond with the cement paste appear to be important parameters in the shear strength contribution of the fibres.

- The load carrying capacity of the beam increased by $12 \%$ on replacement of transverse stirrups by hooked steel fibres, while the use of crimped steel fibres increased the load carrying capacity by $15 \%$.

- Taking all the observations made in the present experimental investigation, it is seen that $1 \%$ of crimped steel fibres of aspect ratio (50) is the best type of steel fibres for replacing transverse stirrups in high strength concrete beams when analysed with the steel fibres and hooked ends. 


\section{References}

[1] F. Sartipi, A. Ghari Zadeh, and M. Gamil, "Electrical resistance of graphene reinforced cement paste," Journal of Construction Materials, 2019.

[2] M. Gamil, A. Ghari Zadeh, and F. Sartipi, "A review on graphene reinforced cement composite: technical approach for ecofriendly construction," Journal of Construction Materials, 2019.

[3] Thomas, J., and Ramaswamy, A., Mechanical Properties of Steel Fiber reinforced Concrete., ASCE Journal of Materials in Civil Engineering,19(5) 2007, PP. 385-392.

[4] Antonie E .Naaman, Engineered Steel Fibers with Optimal Properties for Reinforcement of Cement Composites, Journal of Advanced Concrete Technology, vol.1, No.3, PP 241-252

[5] D. H. Lim, B. H. Oh, Experimental and theoretical investigation on the shear of steel fibre reinforced concrete beams, Eng. Struct. 21 (1999) 37-44.

[6] M. Hamrat, B. Boulekbache, M. Chemrouk, S. Amziane, Shear behaviour of RC beams without stirrups made of normal strength and high strength concretes, Adv. Struct. Eng. 13 (1) (2010) 29-41.

[7] M. K. Johnson, J. A. Ramirez, Minimum shear reinforcement in beams with higher strength concrete, ACl Struct. J. 86 (4) (1989) 376-382.

[8] P. Casanova, P. Rossi, Analysis and design of steel fibre reinforced concrete beams, ACl Struct. J. 94 (5) (1997) 595-602.

[9] R. Narayanan, I. Y. S. Darwish, Use of steel fibres as shear reinforcement, ACl Struct. J. 84 (3) (1987) 216-227.

[10] R. S. Pendyala, P. Mendis, Experimental study on shear strength of high strength concrete beams, ACl Struct. J. 97 (4) (2000) 564-571.

[11] S. Furlan Jr., J.B. de Hanai, Shear behaviour of fibre reinforced concrete beams, Cement Concr. Compos. 19 (1997) 359-366.

[12] S. Shin, S. H. Ghosh, J. Moreno, Flexural ductility of ultra-high strength concrete members, ACl Struct. J. 8 (4) (1989) 394-400.

[13] Julia Sauer, Jan Lingemann, Dipl.-Ing., Oliver Fischer, and Konrad Zilch, "Shear Capacity of Steel Fiber Reinforced Concrete Beams without Stirrups", 3rd fib International Congress 2010.

[14] Mohamed Zakaria, Tamon Ueda, Zhimin Wu and Liang Meng, Experimental Investigation on Shear Crack Behaviour in Reinforced Concrete beams with Shear Reinforcement, Journal of Advanced Concrete Technology, Vol. 7, No.1 February 2009, PP. 79-96. 